\title{
Experimental Study of the Lateral Spreading Pressure Acting on a Pile Foundation During Earthquakes
}

\author{
Takashi Nagao \\ Research Center for Urban Security and Safety \\ Kobe University \\ Kobe City, Japan \\ nagao@people.kobe-u.ac.jp
}

\author{
Daisuke Shibata \\ Engineering Department \\ Japan Port Consultants, Ltd. \\ Tokyo, Japan \\ daisuke_shibata@jportc.co.jp
}

\begin{abstract}
In the seismic design of pile foundations, the safety of the pile is assessed by considering the inertial force during an earthquake and subgrade reaction as external forces against the pile. The amount of deformation of the pile must be limited to a small value to maintain the safety of the pile. In the event of a large earthquake, quay walls and seawalls are subjected to lateral spreading because of the influence of biased seaward earth pressure. The amount of lateral spreading is considerably larger than what can be expected in a typical pile seismic design and may reach several meters. In this study, loading experiments that reproduced lateral spreading were conducted to evaluate the lateral spreading pressure acting on a pile when considerably large lateral spreading occurred. The experiment results showed that lateral spreading pressure depended on the ratio of pile spacing to pile diameter while the peak value of lateral spreading pressure was larger than the one assumed in practical design.
\end{abstract}

Keywords-pile foundation; lateral spreading pressure; subgrade reaction

\section{INTRODUCTION}

In the seismic design of pile foundations, the safety of piles against the inertial forces generated by earthquakes is examined by considering the bending rigidity of a pile and a horizontal subgrade reaction. The horizontal subgrade reaction is obtained by multiplying the horizontal displacement of the pile by the subgrade reaction coefficient corresponding to the ground modulus. The subgrade reaction has an upper limit value, and shear strength of the ground or passive earth pressure is used as the upper limit value in design practice $[1,2]$. As the yielding of the pile is not considered in the design, the deformation of the pile is expected to remain small. Quay walls and seawalls are subjected to large lateral spreading toward the sea because of biased seaward earth pressure and deterioration of ground rigidity due to earthquakes [3-7]. For example, the 1995 South Hyogo Prefecture Earthquake (Kobe Earthquake) caused severe damage to port and harbor structures, and gravity-type quay walls were displaced toward the sea by up to $4 \mathrm{~m}$. Damage to a pile-supported wharf was also confirmed at Takahama pier at the Port of Kobe, and the head and underground parts of the piles suffered buckling. The buckling in the underground parts of the piles was caused by the lateral displacement of the revetment behind the pier on the sea side, the pushing of the rubble layer under the wharf, and the lateral spreading pressure applied to the pile [3]. The lateral spreading pressure that acts on an underground pile during a large earthquake is not taken into account in design practice. Nonlinear finite element analysis (FEA), which models structures and the ground, is sometimes used as a method for evaluating the seismic response of pile foundations during a large earthquake. Nonlinear FEA has the advantage that the nonlinear behavior of the ground and structural members can be expressed, and therefore, the dynamic interaction between the pile and the ground can be considered. Presently, 2D analysis is often used for FEA from the viewpoint of computational load. In 2D FEA, piles discretely arranged must be modeled as a continuous wall having equivalent rigidity per unit depth. When foundation piles are affected by lateral spreading, the ground on the front of the piles exerts lateral spreading pressure on the piles while the ground between the piles slips between them. Such a 3D effect cannot be accurately reproduced by a $2 \mathrm{D}$ analysis in which the piles are modeled as a continuous wall. Attempts have been made to include a soil spring element as a method of expressing $3 \mathrm{D}$ effects in a $2 \mathrm{D}$ analysis $[8,9]$. In such a model, the soil spring element is interposed between the pile and the ground to transmit the load mutually. 2D nonlinear FEA examples using soil spring elements for pile-supported wharves have been studied [10-12]. However, some point out that 3D effects cannot be sufficiently reproduced by such a $2 \mathrm{D}$ analysis [12]. The deviation between a physical 3D model and the assumptions made in design calculations is expected to be a serious problem in the case of lateral spreading, which can reach several meters in the event of a massive earthquake.

Many experimental studies have been conducted on the dynamic interaction between the pile and the ground where the subgrade reaction was measured by shaking table and horizontal loading tests at the pile heads $[13,14]$. However, the displacement of piles during an earthquake is very small because of their high rigidity compared with the amount of lateral spreading. To the best of our knowledge, no studies exist in which the lateral spreading pressure was examined during large-scale lateral spreading. In this study, a horizontal loading experiment of the ground against a pile was performed to evaluate the characteristics of lateral spreading pressure acting on the pile foundation in case of large lateral spreading. 


\section{METHOD}

\section{A. Outline of the Experiment}

The experiment was carried out using a soil tank shown in Figures 1-2. A steel model pile with a length of $200 \mathrm{~mm}$ was bolted onto the soil tank slab with a width of $1000 \mathrm{~mm}$ and a depth of 500mm (Figure 3). Using two loading plates and fixed rods, a soil tank frame with internal dimensions of $500 \mathrm{~mm}$ width, $500 \mathrm{~mm}$ depth, and $500 \mathrm{~mm}$ height was constructed in the soil tank. Horizontal displacement was applied to the model ground in the soil tank frame by horizontally loading the loading plate with a mega torque motor, and the situation in which the ground slipped through the spaces between the piles during lateral spreading was reproduced.

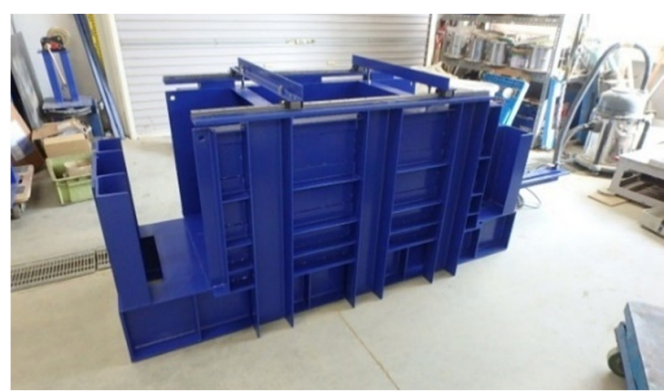

Fig. 1. Photo of the soil tank
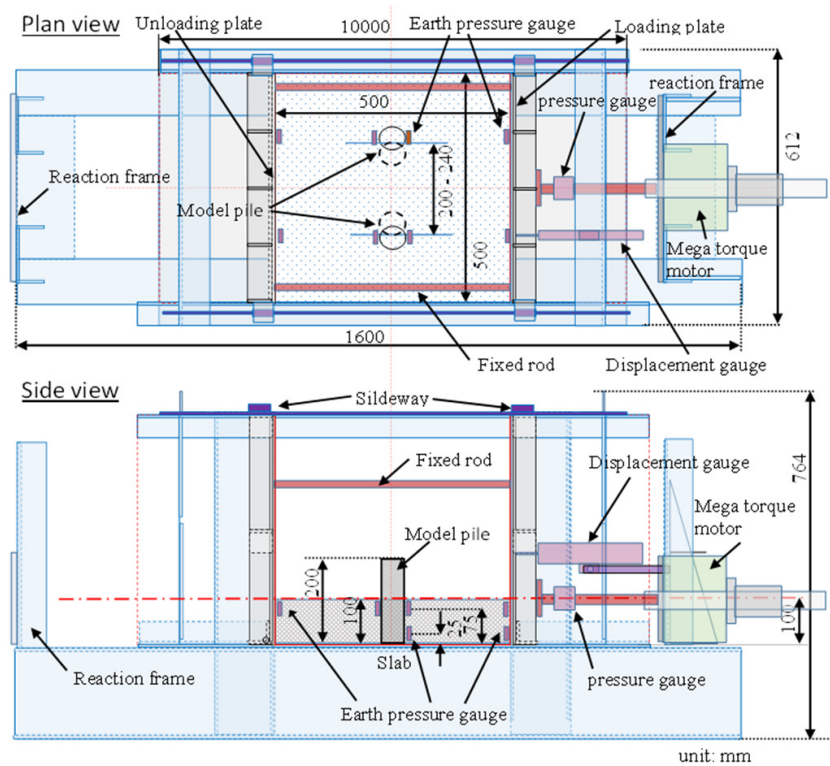

Fig. 2. Experimental soil tank

Steel pipe piles and concrete piles with diameters of the order of $1 \mathrm{~m}$ cannot withstand large lateral spreading pressure. Therefore, in this experiment, a reinforced concrete caisson was assumed as a foundation pile. Considering the dimensions of the caisson foundation in the field and the size of the experimental soil tank, the length scaling factor (prototype/model) was set to 100 , and the model specifications were determined by applying the similitude for shaking table tests on a soil-structure-fluid model in a $1 \mathrm{~g}$ gravitational field
$[15,16]$. Five experimental cases were examined with varying pile diameters and spacing (Table I). According to the similitude, the pile diameter and the pile spacing are 100 times larger in the actual scale.

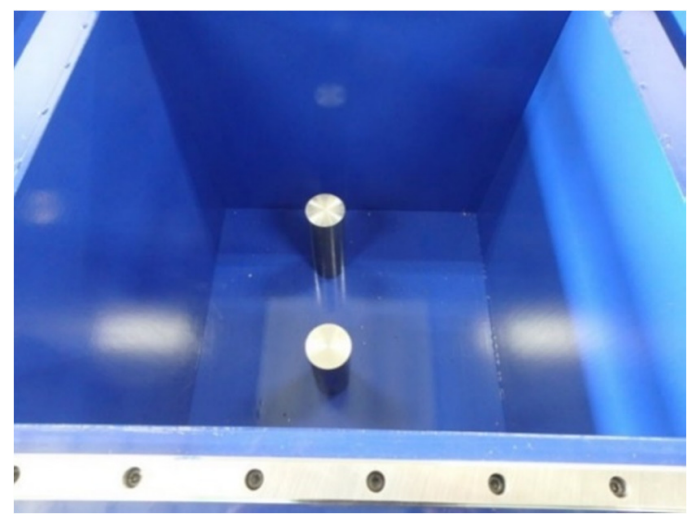

Fig. 3. Pile model installation status

The horizontal loading speed applied to the model ground was set to $20 \mathrm{~cm} / \mathrm{s}$ on the actual scale with reference to past seismic response analyses. The loading speed in the experiment was $1 / 31.6$ of the actual scale from the similitude. The maximum moving distance was $10 \mathrm{~cm}$, which corresponds to $10 \mathrm{~m}$ on the actual scale. The ground was prepared by air pluviation so that the relative density $\left(D_{r}\right)$ was approximately $75 \%$, using Tohoku Silica Sand No. 6 in the dry state. The relative density during the actual experiments was $D_{r}=74.0 \%$ $77.8 \%$. The sand depth was $100 \mathrm{~mm}$.

TABLE I. TEST CASES

\begin{tabular}{|c|c|c|}
\hline & Diam eter $\mathbf{( m m )}$ & Spacing $\mathbf{( m m})$ \\
\hline case 1 & 55 & 200 \\
\hline case 2 & 55 & 240 \\
\hline case 3 & 60 & 220 \\
\hline case 4 & 65 & 200 \\
\hline case 5 & 65 & 240 \\
\hline
\end{tabular}

\section{B. Measured Items}

The items measured in these experiments were i) lateral spreading pressure and wall earth pressure, ii) horizontal displacement, iii) load on the loading side wall, and iv) ground surface vertical displacement after loading. Time-history data were recorded by a data logger for i) through iii). The lateral spreading pressure was measured using earth pressure gauges attached to the model piles using a fitting jig. These were installed at a height of $25 \mathrm{~mm}$ and $75 \mathrm{~mm}$ from the bottom slab on the loading side and at a height of $75 \mathrm{~mm}$ from the bottom slab on the unloading side. Gauges for measuring the wall earth pressure were installed at heights of $25 \mathrm{~mm}$ and $75 \mathrm{~mm}$ from the bottom slab on the loading side and at $75 \mathrm{~mm}$ from the bottom slab on the unloading side (Figure 2). Five traverse lines with the same elevation positions from the loading side wall to the unloading side wall were constructed using sewing threads to measure the vertical displacement of the ground surface after loading. The vertical displacement was obtained by measuring the vertical distance from the traverse line to the model ground surface using a measuring scale with an accuracy of $1 \mathrm{~mm}$. In 
addition, colored sand was laid on the ground surface at equal intervals perpendicular to the traverse line to monitor the ground slip between the piles. The deformation of the colored sand was monitored by a video camera installed above the test equipment.

\section{RESULTS AND DISCUSSION}

\section{A. Lateral Spreading Pressure}

The earth pressure gauge readings fluctuated drastically due to the frictional resistance acting on the soil tank frame and the sand during loading and the consecutive cycles of locking and slipping of the sand particles. Therefore, the measured data were Fast Fourier transformed, and after performing low-pass filtering at $1 \mathrm{~Hz}$, the inverse Fast Fourier transform was taken to obtain smooth time-history data. Figure 4 shows an example of the result of this smoothing process using data from the upper part of the pile for Case 4 . The gray line denotes the measured data, and the red solid line is the data after the filtering process. The same processing was performed on all measured data.

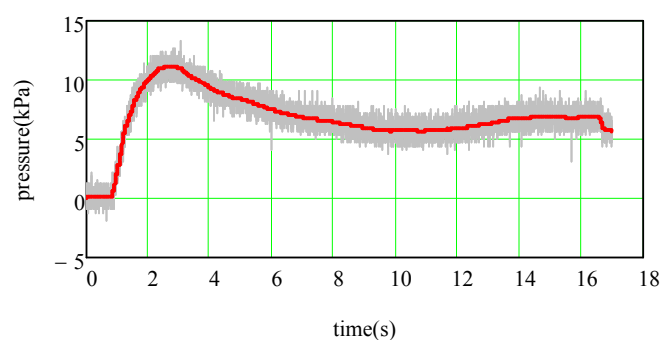

Fig. 4. Example of filtering (Case 4)

Figure 5 shows the lateral spreading pressure on the loading side. The blue line represents the lateral spreading pressure at the lower part of the pile, the red line denotes the lateral spreading pressure at the upper part of the pile, the dotted line shows the lateral spreading pressure on each of the two piles, and the solid line is the average value. The circles indicate the values at which the lateral spreading pressure peaks first. All the lateral spreading pressures shown in this study indicate increments from the pre-load. The lateral spreading pressures at the upper sensors decreased after they peaked at a displacement of around $10 \mathrm{~mm}-15 \mathrm{~mm}$ and became almost constant for displacements larger than $50 \mathrm{~mm}$. The lateral spreading pressure at the lower part also showed a peak in the vicinity of $10 \mathrm{~mm}-15 \mathrm{~mm}$ and thereafter remained almost constant without significantly decreasing, before gradually increasing in the displacement range over $40 \mathrm{~mm}$ to the end of loading. When the lateral spreading pressure first peaks, the ground displacement is $1-2 \mathrm{~m}$ when converted to the local scale, and it is almost the same as the lateral spreading displacement experienced by the quay wall and the revetment when large earthquake ground motions are applied. Therefore, this value will be referred to as the "peak lateral spreading pressure" in the following discussion. The earth pressures on the unloading side of the pile and the unloading side of the wall were almost zero during loading, because the high rigidity of the pile results in a small bending deformation of the pile in comparison to the ground deformation, so the subgrade reaction does not act on the back surface of the pile.
Case 1

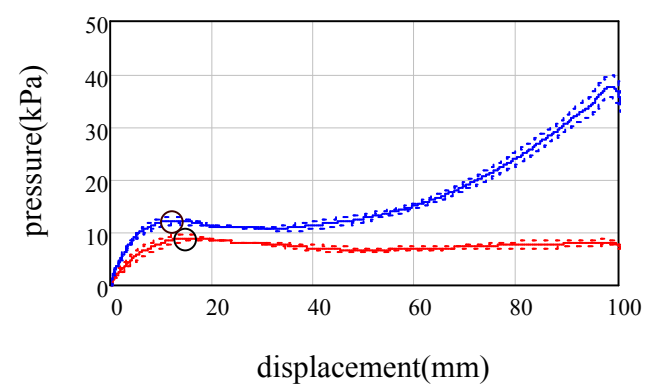

Case 2

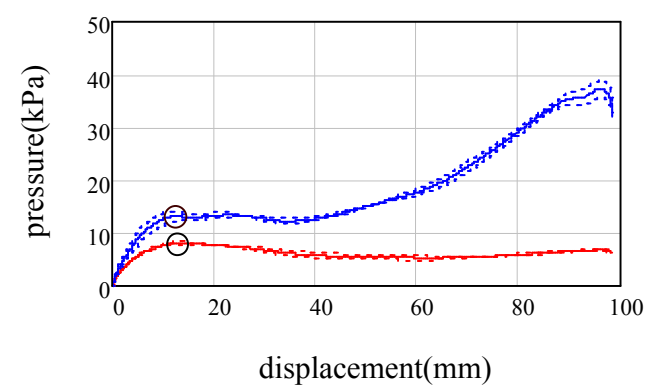

Case 3

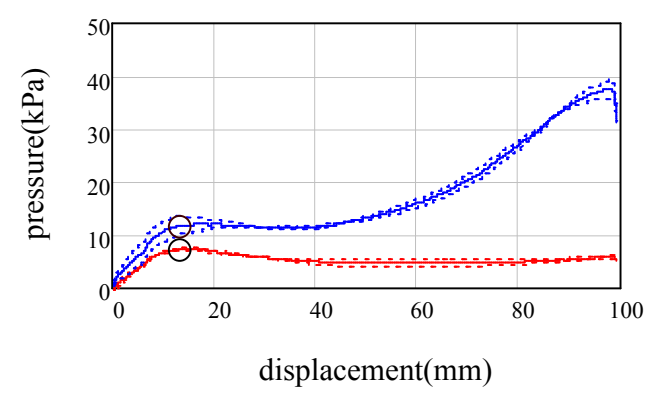

Case 4

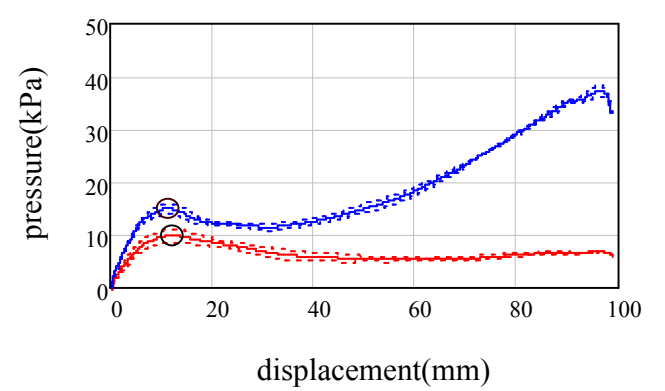

Case 5

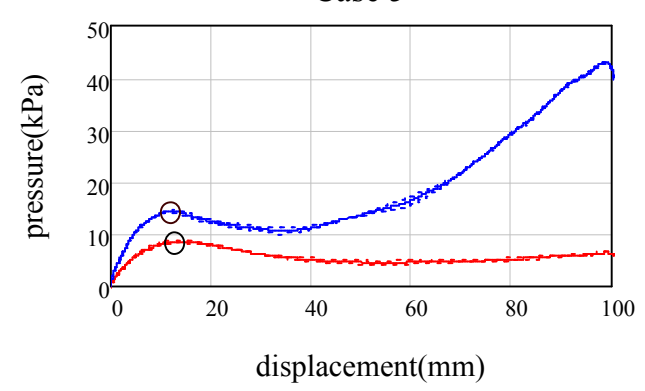

Fig. 5. Lateral spreading pressure 
Figure 6 shows the relationship between the peak value of the lateral spreading pressure and the pile diameter, and Figure 7 illustrates the relationship between the peak lateral spreading pressure and the pile spacing. The red triangles indicate the values at the upper part of the pile, and the blue circles denote the values at the lower part of the pile. The pile spacing is defined as the distance between the outer surfaces of the piles, not the distance between the centers of the piles, because this expresses the space available for the ground to pass between the piles. Although the peak lateral spreading pressure appears to be positively correlated with the pile diameter and negatively correlated with the pile spacing, the relationship is not clear. The larger the diameter of the pile, the greater the degree to which the pile becomes a barrier to the lateral spreading of the ground, and the wider the interval between the piles, the greater the lateral spreading of the ground. Therefore, the ratio of the pile spacing to the pile diameter (SDR) is proposed to express the magnitude of the peak lateral spreading pressure. Figure 8 illustrates the relationship between SDR and the peak lateral spreading pressure. The fact that the peak lateral spreading pressure depends on SDR is clear.

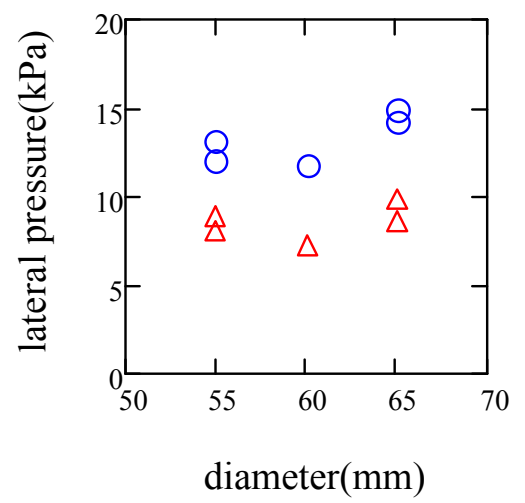

Fig. 6. Relationship between peak lateral spreading pressure and pile diameter

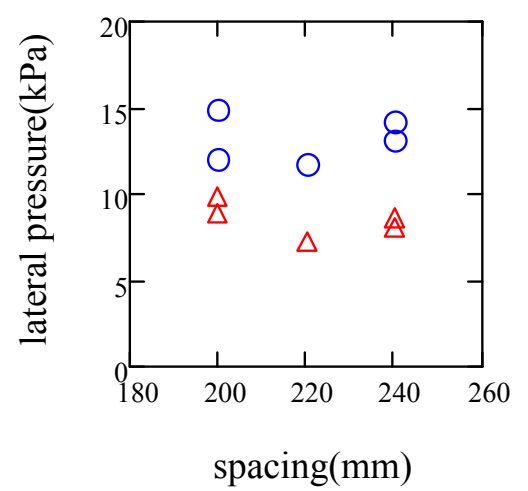

Fig. 7. Relationship between peak lateral spreading pressure and pile spacing

As described above, the wall earth pressure on the unloading side was almost zero during loading, but it increased with loading on the loading side. The relationship between the wall earth pressure on the loading side and the lateral spreading pressure is shown in Figure 9, taking Case 4 as an example. Red lines indicate the pressure in the upper part, blue lines denote the pressure in the lower part, solid lines express the values of the pile, and dotted lines indicate the value of the wall. The wall earth pressure peaks before the lateral spreading pressure of the pile, and the peak wall earth pressure is lower than the peak lateral spreading pressure. In addition, the wall earth pressure decreases after reaching a peak, as does the lateral spreading pressure on the upper part of the pile, and subsequently shows an almost constant value.

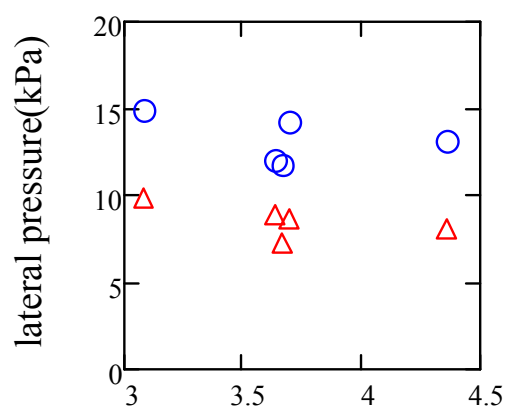

spacing/diameter

Fig. 8. Relationship between peak lateral spreading pressure and SDR

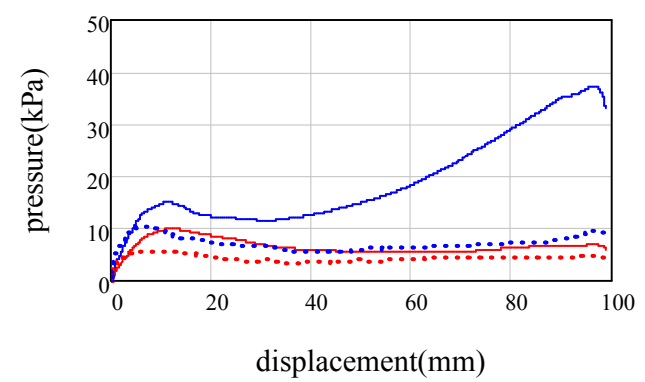

Fig. 9. Relationship between wall earth pressure and lateral spreading pressure (Case 4)

Figure 10 shows the relationship between the peak wall earth pressure and the peak lateral spreading pressure in the range of displacement up to $20 \mathrm{~mm}$ in all cases.

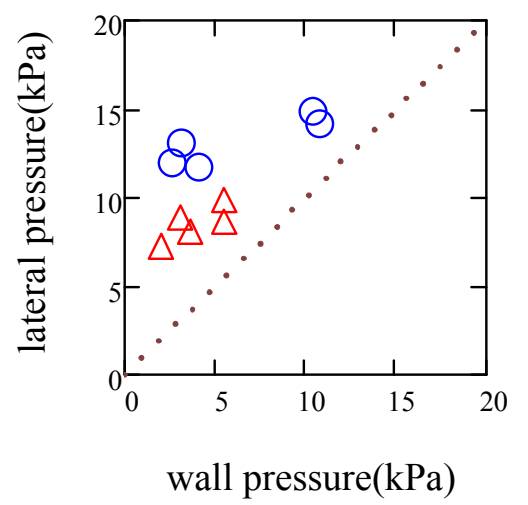

Fig. 10. Relationship between peak wall earth pressure and peak lateral spreading pressure 
The dotted line is a 1:1 auxiliary line. The larger the peak lateral spreading pressure, the larger the peak wall earth pressure. The results indicate that the influence of the lateral spreading pressure acting on the piles extends to the loading side wall. The rapid increase in wall earth pressure immediately after loading indicates that the ground between the pile and the loading wall is compressed. The reason the wall earth pressure decreased after the peak was that the soil around the piles moved along the pile surface while the soil between the piles slipped through the pile space.

\section{B. Horizontal Displacement}

Figure 11 shows a planar image after loading, taking Case 2 as an example. Figure 12 shows the displacement of the soil on the ground surface by measuring the displacement of the colored sand along traverse lines $1-5$. Blue dotted lines indicate the positions before loading and red solid lines denote the positions after loading. In traverse lines 2 and 4, where the piles are located, the pile resisted the displacement of the soil and it was compressed, so the intervals between the colored sand lines at the front surface of the pile were narrower after the loading than before the loading. Conversely, in traverse lines 1 and 5, where no pile was present, the soil was minimally displaced and there was almost no difference in the interval between the colored sand at the front surface of the pile before and after the experiment. This trend was the same for all cases. In traverse line 3 , between the piles, the amount of movement of the inter-pile soil differed depending on the pile spacing and diameter.

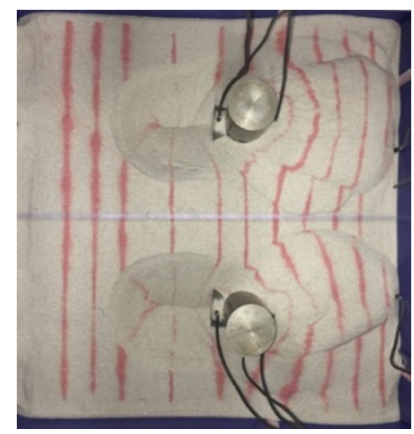

Fig. 11. Post-load plane (Case 2)

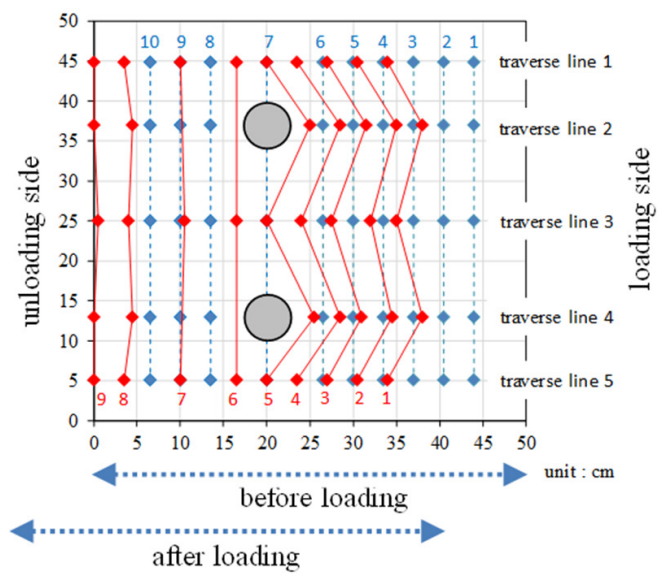

Focusing on the fifth colored sand line from the loading side wall at traverse line 3 , between the piles, the displacement of the colored sand after loading was used to define the amount of soil displacement between piles. Figure 13 shows the relationship between the amount of soil displacement between the piles and SDR. Although the amount of soil displacement between the piles tends to increase as SDR increases, the correlation between the two is not strong.

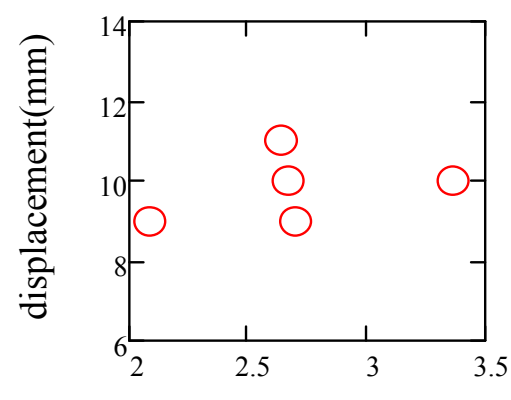

spacing / diameter

Fig. 13. Relationship between soil displacement between the piles and SDR

\section{Vertical Displacement}

Figure 14 shows Case 2 as an example of the vertical displacement of the ground surface after loading. The horizontal axis is the distance from the unloading side wall. The gray hatching indicates the location of the piles. In traverse lines 2 and 4, where the piles are located, the ground surface after loading has risen on the loading side and subsided on the unloading side. As confirmed from the image captured by the video camera, no remarkable rise in the ground surface occurred in the range of horizontal displacement of $10 \mathrm{~mm}$ to $15 \mathrm{~mm}$, and vertical displacement occurred when the horizontal displacement was about $20 \mathrm{~mm}$ or more. In comparison, in traverse lines 1, 3, and 5, away from the piles, the ground surface on the loading side rose after loading as in traverse lines 2 and 4, in line with the piles, but almost no vertical displacement occurred on the unloading side. This trend was the same for all cases.

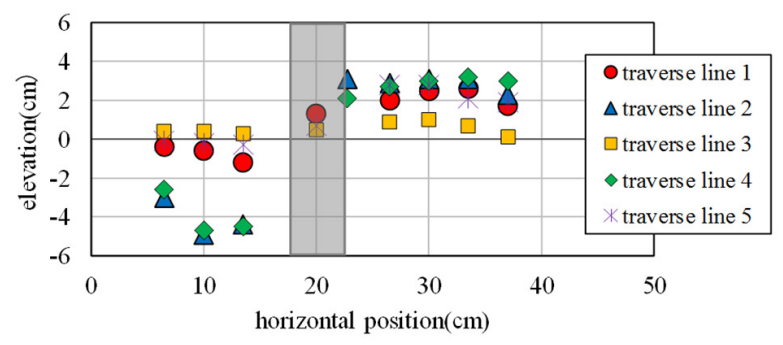

Fig. 14. Vertical displacement of ground surface after loading (Case 2)

Figure 15 shows the relationship between the amount of ground rise and SDR. The red triangles denote the average values on the loading side, and the blue circles indicate the values of traverse line 3 , between the two piles. There is no correlation between the amount of ground rise and SDR.

Fig. 12. Horizontal displacement of ground surface after loading (Case 2) 


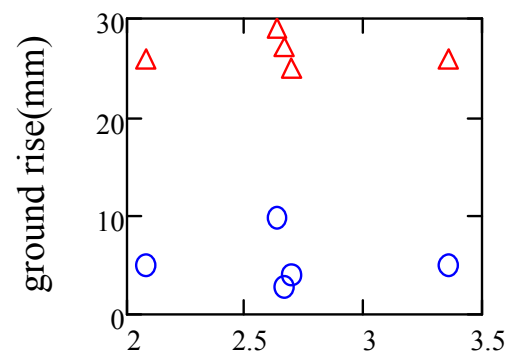

spacing/diameter

Fig. 15. Relationship between the ground rise and SDR

\section{DISCUSSION ON LATERAL SPREADING PRESSURE}

As a range for the assumed normal lateral spreading amount, the lateral spreading pressure for ground displacement up to an experimental value of about $40 \mathrm{~mm}$ will be discussed. As already mentioned, lateral spreading pressure peaks at the same level of ground displacement in both the upper and lower parts of the pile, but the lateral spreading pressure at the upper part decreases after the peak, whereas the lateral spreading pressure at the lower part becomes almost constant after the peak. This results in the ground in front of the pile on the loading side rising, which indicates that it has been compressed. This is the reason the lateral spreading pressure increases in both the upper and lower parts, but in the upper part, the compressed and raised soil gradually moves from the front surface of the pile to the side surface and eventually slides out behind the pile. For this reason, the effect of ground compression is alleviated, and the lateral spreading pressure does not increase after the peak. Since the effect of relaxation of the ground compression due to slip-through is especially large in the upper part, the lateral spreading pressure decreases after peaking. In the lower part, since the relaxation effect of the ground compression is small, the value is almost constant after the peak. In seismic design of a structure having a pile foundation, the soundness of the pile is checked by applying the subgrade reaction due to the deformation of the pile as a force in a direction perpendicular to the axis. The subgrade reaction is calculated by multiplying the subgrade reaction coefficient by the displacement of the pile, and the upper limit of the subgrade reaction is either the shear strength of the ground or the passive earth pressure. This paper compares the values measured by experiment with those calculated using the conventional design method. Evaluation of the subgrade reaction coefficient is based on the technical standards for port and harbor structures in Japan [16] as:

$$
k_{h}=1.5 \mathrm{~N}
$$

where $k_{h}$ is the coefficient of horizontal subgrade reaction $\left(\mathrm{N} / \mathrm{cm}^{3}\right), N$ is the average $N$-value of the ground down to a depth of about $1 / \beta$, and $\beta$ is the characteristic value of the pile, which is calculated as:

$$
\beta=\left(k_{h} D / 4 E I\right)^{1 / 4}
$$

where $D$ is the diameter of the pile (cm), and $E I$ is the flexural rigidity of the pile $\left(\mathrm{Ncm}^{2}\right)$.
Case 1

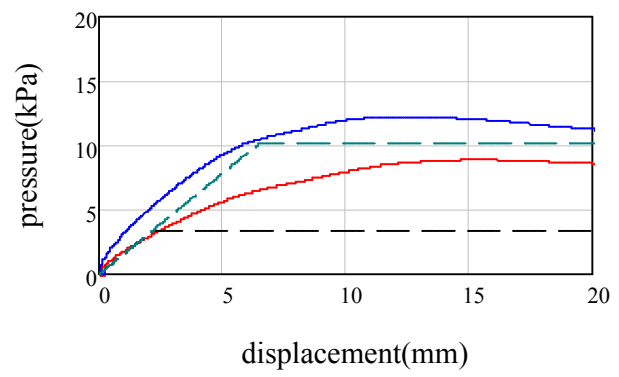

Case 2

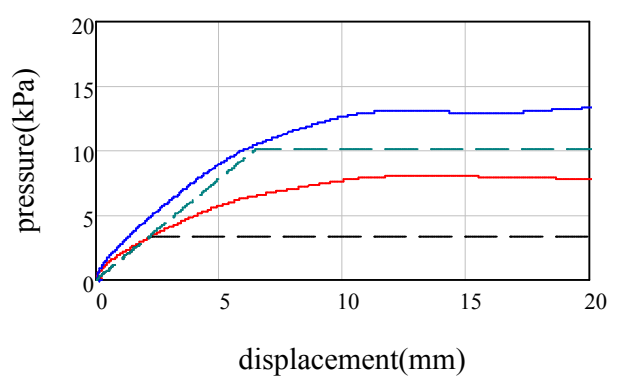

Case 3

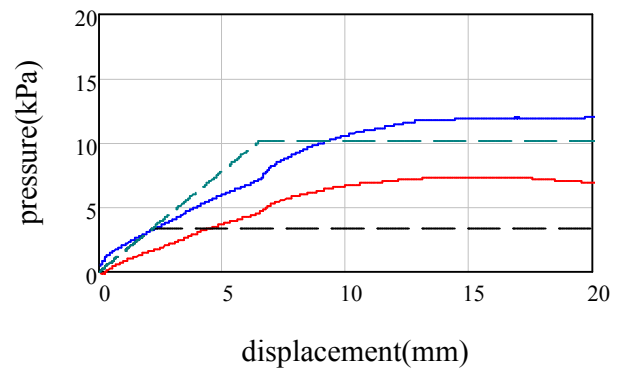

Case 4

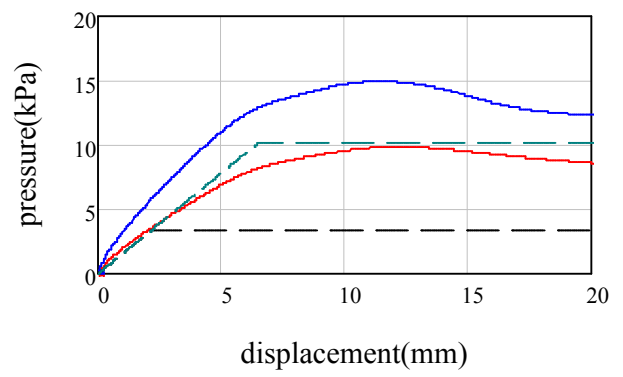

Case 5

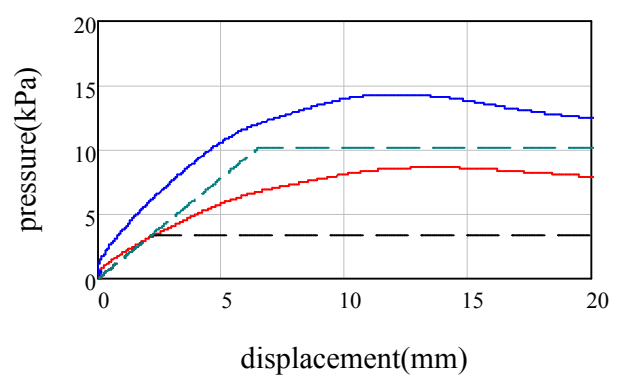

Fig. 16. Comparison of lateral spreading pressure experimental values and design values 
In the calculation of soil parameters, $N$-values were obtained from $D_{r}$ in accordance with [17] as:

$$
D_{r}=21\left\{N /\left(\sigma v^{\prime}+0.7\right)\right\}^{0.5}
$$

where $D_{r}$ is the relative density (\%), $N$ is the $N$-value of the soil, and $\sigma v^{\prime}$ is the effective vertical stress of the soil $\left(\mathrm{kgf} / \mathrm{cm}^{2}\right)$.

The upper limit of the subgrade reaction force was calculated as the passive earth pressure. The shear resistance angle required for the calculation of the passive earth pressure coefficient was obtained from the relative density by referring to [17] as:

$$
\phi=0.0003 D_{r}^{2}+0.0426 D_{r}+36.682
$$

where $\phi$ is the shear resistance angle $(\mathrm{deg})$, and $D_{r}$ is the relative density $(\%)$.

A comparison of the experimental and design values of the lateral spreading pressure is shown in Figure 16. The red solid line represents the experimental value at the upper part of the pile, the blue solid line denotes the experimental value at the lower part of the pile, the broken black line represents the design value at the upper part of the pile, and the broken green line denotes the design value at the lower part of the pile. The design value shows reasonably good correspondence with the experimental value in the range up to the upper limit value, but the design subgrade reaction upper limit value is small in comparison with the peak lateral spreading pressure, especially in the upper part of the pile.

Figure 17 shows a comparison between the design subgrade reaction upper limit value and the lateral spreading pressure peak value for all cases. The red triangles represent the values at the upper part of the pile, and the blue circles are the values at the lower part of the pile. The conventional design method underestimates the upper limit of the lateral spreading pressure, and when large-scale lateral spreading occurs, the conventional design method falls on the dangerous side. The passive earth pressure is a calculation model for a continuous wall, and a uniform stress state is assumed in the depth direction. However, in reality the ground around the pile is in a highly inhomogeneous state, and strong stress concentration occurs around the pile. Therefore, current design methods underestimate the peak lateral spreading pressure.

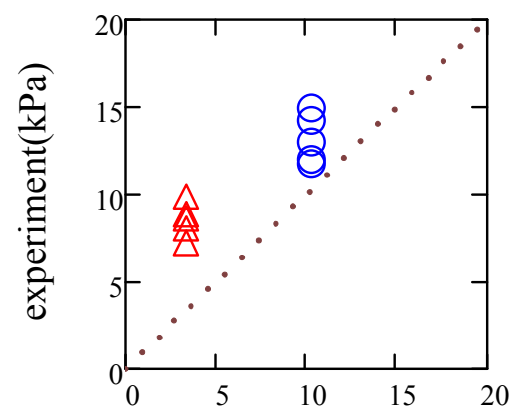

design value $(\mathrm{kPa})$

Fig. 17. Comparison of lateral spreading pressure peak values and design values

\section{CONCLUSION}

In this paper, experiments examining the horizontal loading of the ground against pile foundations were carried out to understand the relationship between the ground displacement by lateral spreading and the lateral spreading pressure acting on the pile foundation. The main conclusions drawn from the study are:

- The lateral spreading pressure increases with increasing horizontal displacement after loading and peaks at a horizontal displacement of about $10-15 \mathrm{~mm}(1.0-1.5 \mathrm{~m}$ on the field scale). After the occurrence of the peak, the lateral spreading pressure gradually decreases at a position close to the ground surface but becomes almost constant at a deep position. After the lateral spreading pressure peaks, the surface of the ground on the loading side of the pile rises. The lateral spreading pressure increases with the increase of the horizontal displacement immediately after loading because the ground in front of the pile is compressed, and the compressed and raised soil gradually moves from the front to the side of the pile at a position close to the ground surface after a peak in pressure. For this reason, the effect of ground compression is alleviated, and the lateral spreading pressure does not increase after the peak. This relaxation effect due to ground slip-through is especially large at a position close to the ground surface, and, therefore, the lateral spreading pressure decreases after a peak is reached. Since this relaxation effect is small at a deep position, the pressure remains substantially constant after the peak is exhibited.

- The peak value of the lateral spreading pressure depends on the pile spacing to diameter ratio (SDR), and the smaller the $\mathrm{SDR}$, the larger the peak lateral spreading pressure. This is because the smaller the SDR, the greater the degree to which the pile becomes a barrier to ground deformation.

- As a result of comparing the relationship between the horizontal displacement of the ground and the lateral spreading pressure with the relationship assumed by the conventional design method, the design method agrees with the experimental results until the lateral spreading pressure peaks. However, with respect to the peak value of the lateral spreading pressure, the design method underestimates the experimental value. The degree of this underestimation is particularly exhibited at a position close to the ground surface, and it is necessary to appropriately evaluate the peak value of the lateral spreading pressure in case a large lateral spreading occurs in the event of an earthquake.

\section{ACKNOWLEDGMENT}

This work was supported by JSPS KAKENHI, Grant Number JP18K04324. The authors thank Dr. Masahiko Oishi of Oriental Shiroishi Co., Ltd., for his valuable opinions on the implementation of this study.

\section{REFERENCES}

[1] American Association of State Highway and Transportation Officials, AASHTO LRFD Bridge design specifications, Seventh Edition, with 2015 Interim Revisions, AASHTO, 2014 
[2] Japan Road Association, Specifications for highway bridges, Part 4, substructures, ver. 2012, Maruzen Co., Ltd., 2016

[3] International Navigation Association (PIANC), Seismic design guidelines for port structures, A.A. Balkema Publishers, 2001

[4] G. Mondal, D. C. Rai, "Performance of harbour structures in Andaman Islands during 2004 Sumatra earthquake", Engineering Structurs, Vol. 30, No. 1, pp. 174-182, 2008

[5] R. A. Green, S. M. Olson, R. Brady, B. R. Cox, G. J. Rix, E. Rathje, J. Bachhuber, J. French, S. Lasley, N. Martin, "Geotechnical aspects of failures at Port-au-Prince seaport during the 12 January 2010 Haiti earthquake", Earthquake Spectra, Vol. 27, No. S1, pp. S43-S65, 2011

[6] S. Werner, N. McCullough, W. Bruin, A. Augustine, G. Rix, B. Crowder, J. Tomblin, "Seismic performance of Port de Port-au-Prince during the Haiti Earthquake and post-earthquake restoration of cargo throughput", Earthquake Spectra, Vol. 27, No. S1, pp. S387-S410, 2011

[7] T. Sugano, A. Nozu, E. Kohama, K. Shimosako, Y. Kikuchi, "Damage to coastal structures", Soils and Foundations, Vol. 54, No. 4, pp. 883901,2014

[8] O. Ozutsumi, Y. Tamari, Y. Oka, K. Ichii, S. Iai, Y. Umeki, "Modeling of soil-pile interaction subjected to soil liquefaction in plane strain analysis", 38th Annual Conference of Japan Geotechnical Society, Akita, Japan, July 2-4, 2003 (in Japanese)

[9] S. Miwa, O. Ozutsumi, Y. Tamari, Y. Oka, S. Iai, S. Tagawa, "Twodimensional analysis of horizontal cross section for soil-pile interaction in liquefied ground", 38th Annual conference of Japan Geotechnical Society, Akita, Japan, July 2-4, 2003 (in Japanese)

[10] S. Iai, "Seismic analysis and performance of retaining structures", Geotechnical Earthquake Engineering and Soil Dynamics III, Seattle, United States, August 3-6, 1998

[11] A. Takahashi, J. Takemura, "Liquefaction-induced large displacement of pile-supported wharf", Soil Dynamics and Earthquake Engineering, Vol. 25, pp. 811-825, 2005

[12] G. Li, R. Motamed, "Finite element modeling of soil-pile response subjected to liquefaction induced lateral spreading in a large-scale shake table experiment", Soil Dynamics and Earthquake Engineering, Vol. 92, pp. 573-584, 2017

[13] W. Chang, J. Chen, H. Ho, Y. Chiu, "In Situ Dynamic Model Test for Pile-Supported Wharf in Liquefied Sand", Geotechnical Testing Journal, Vol. 33, No. 3, pp. 212-224, 2010

[14] L. Su, L. Tang, X. Ling, C. Liu, X. Zhang, "Pile response to liquefaction-induced lateral spreading: a shake-table investigation", Soil Dynamics and Earthquake Engineering, Vol. 82, pp. 196-204, 2016

[15] P. Yin, W. He, ZJ. Yang, "A Simplified Nonlinear Method for a Laterally Loaded Pile in Sloping Ground", Advances in Civil Engineering, Vol. 2018, Article ID 5438618, 2018

[16] S. Iai, "Similitude for Shaking table test on Soil-Structure-Fluid Model in 1g Gravitational Field", Soil and Foundations, Vol. 29, No. 1, pp. 105-118, 1989

[17] Ports and Harbours Bureau, Ministry of Land, Infrastructure, Transport and Tourism, National Institute for Land and Infrastructure Management, Port and Airport Research Institute, Technical standards and commentaries for port and harbour facilities in Japan, The Overseas Coastal Area Developement Institute of Japan, 2009

[18] T. Morita, S. Iai, H. Liu, K. Ichii, Y. Sato, Simplified method to determine parameter of FLIP, Technical Note of the Port and Harbor Research Institute, No.869, 1997 (in Japanese) 